\title{
A Molecular Mechanics (MM2) Study of Furan, Thiophene, and
}

\section{Related Compounds}

\author{
Julia C. Tai \\ University of Michigan-Dearborn, Dearborn, Michigan 48128
}

Jenn-Huei Lii and Norman L. Allinger

School of Chemical Sciences, University of Georgia, Athens, Georgia 30602

Received 20 May 1988; accepted 14 November 1988

The molecular mechanics calculations reported earlier for nitrogen heterocycles have now been extended to include the title compounds, and related molecules. It is in general possible to calculate these structures with an accuracy that compares favorably with experiment.

\section{INTRODUCTION}

The MM2 force field has been widely used for the determination of structures by the molecular mechanics method (MM2). ${ }^{1}$ It was developed to be applicable to conjugated hydrocarbons many years ago, ${ }^{1,2}$ and this version of the program was called MM2(82). The procedure by which pi system heteroatoms may be incorporated into the MM2 frame work was described in an earlier paper, ${ }^{3}$ where we reported the study of heterocyclic compounds containing nitrogen atoms. The geometries of compounds containing pyridine and pyrrole type nitrogen atoms were calculated quite well using the procedure developed. In this article, we shall describe the application of this procedure to the structural study of furan and thiophene, and related compounds. ${ }^{4}$

To develop the parameters for the furan type oxygen atom, our original search for structural data was focused on compounds with an oxygen atom located in an aromatic ring. However, since only three such compounds of known geometry were found, namely: furan, benzofuran, and dibenzo- $p$ dioxin, it was felt necessary to employ other similar compounds. A molecular mechanics study of methyl vinyl ether and related compounds using the MM2 (1977) program was described in an earlier paper. ${ }^{5}$ It was decided that the model compounds used there be included to broaden the parameterization base. These include $s$-cis-vinyl alcohol, phenol, $s$-cis-methyl vinyl ether, anisol, and 1,4dioxene. It should be pointed out that in the earlier MM2 calculations, pi electron delocalization was not explicitly treated, and an oxygen atom assumes an effectively tetrahedral structure with two electron lone pairs. This approximation is adequate for vinyl ether type structures. However, when the oxygen is part of a more extended conjugated system as in furan, a more general treatment is necessary, and in this model the oxygen atom assumes a planar sigma structure with a lone pair of electrons in the plane and a $p$-orbital perpendicular to the plane and contributing two electrons to the pi system. Because of these differences, most of the parameters derived in the earlier paper can not be adopted here, and a different "atom type" is assigned to the oxygen. (Type 6 is used for ordinary ether oxygen, and for simple vinyl ethers treated as unconjugated, and type 41 is used for furan oxygen.) $\mathrm{Pa}$ rameters that are not affected by the differences mentioned could be adopted with little modification.

The geometry of thiophene and six other related compounds were used to develop parameters for the sulfur atom in a conjugated system. In this model the sulfur atom also assumes a planar sigma structure but the lone pair orbital was not explicitly included in the treatment. 
The structural formulas and the numbering of atoms are given in Figures 1 and 2 . Note that the numbering systems used here were chosen for computational convenience and are not the same as the nomenclature numbering systems.

The new parameters developed for these two types of atoms are collected in Table 1. A description of the procedure employed in arriving at these values and a discussion of the results will follow.

\section{VAN DER WAALS AND PI-SYSTEM PARAMETERS}

The pi parameters required for each heteroatom are: the effective nuclear charge, $Z$; the ionization potential, $I$; and the one center repulsion integral, $\gamma$. The furan-type oxygen atom has a valence state electronic configuration of $\left(\operatorname{tr} \operatorname{tr} \operatorname{tr}^{2} \pi^{2}\right)$. The measured valence state ionization potential is $15.30 \mathrm{eV}^{6}$ and the estimated value of $\gamma$ is $19.342 \mathrm{eV} .^{7}$ The Slater charge 4.55 is taken to be the effective nuclear charge. These values were used in preliminary studies of furan. It was soon discovered that the difference of the two types of $\mathrm{C}-\mathrm{C}$ bond lengths (2-3 and 3-4) in furan could not be predicted correctly. The shorter $\mathrm{C}-\mathrm{C}$ bond was calculated to be too long by ca. $0.01 \AA$ and the longer one too short by ca. $0.01 \AA$. It was also found that including nonneighbor resonance integrals and/or increasing the value of $I$ could improve the results. Since the former procedure is not easily incorporated in the framework of the present program, it was decided to treat the $I$ as an adjustable parameter. The value decided upon is $17.60 \mathrm{eV}, 15 \%$ higher than the experimental value of 15.30 $\mathrm{eV}$ for a free oxygen atom of the same valence state. A similar problem and its solu-

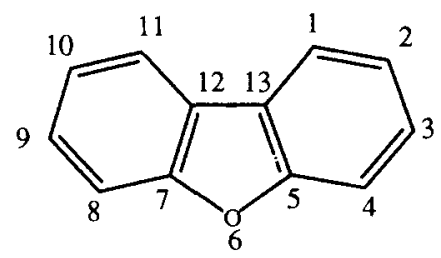

Dibenzofuran<smiles>c1ccc2c(c1)Oc1ccccc1O2</smiles>

Dibenzo-p-dioxin

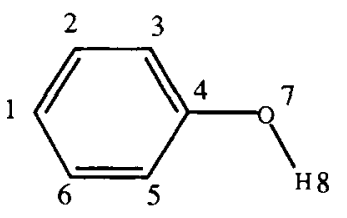

Phenol



Anisol



cis-Vinyl alcohol

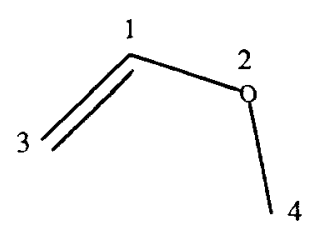

cis-Methyl vinyl ether



1,4-Dioxene

Figure 1. Furan and related compounds 


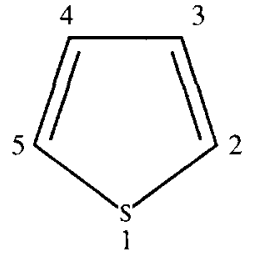

Thiophene



trans-2,2'-Bithiophene



Dibenzothiophene

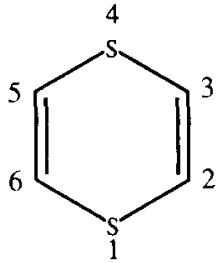

1,4-Dithiadiene<smiles></smiles>

1,4-Thiophthene<smiles>Cc1ccccc1Sc1ccccc1</smiles>

Thianthrene



trans-1,2-Bis(2-thienyl)ethylene

Figure 2. Thiophene and related compounds

tion were found in the calculation of the geometry of pyrrole. ${ }^{3}$ Since the oxygen $\pi$ orbital contributes two electrons to the $\pi$ system, it has a positive $\pi$ electron charge. Using a higher ionization potential has an effect similar to that which would be obtained by a variable electronegativity SCF treatment. ${ }^{7,35}$ The same is true for any $\pi$ orbital contributing two electrons such as the pyrrole nitrogen or the thiophene sulfur. The van der Waals radius and energy used are the same as those for the ether and alcohol oxygen. ${ }^{5}$

The van der Waals radius and energy for sulfide type sulfur were adopted for thiophene type sulfur (atom type 42). The valence state of the S-atom is ( $\operatorname{tr} \operatorname{tr} \operatorname{tr}^{2} \pi^{2}$ ). The first and second valence state ionization potentials were calculated to be 10.96 and $22.88 \mathrm{eV}$ respectively, using information given by Hinze and Jaffe. ${ }^{6}$ The difference of the two ionization potentials is set equal to the one-center repulsion integral. Again, it was found necessary to employ a larger value as the first ionization potential in order to obtain a good geometry for thiophene. Thus the value of $15.8 \mathrm{eV}$ was arrived at.

\section{THE STRETCHING PARAMETERS}

For the oxygen compounds, parameters for four types of bond need to be determined, these are the $\mathrm{C}_{s p}{ }^{2}-\mathrm{O}\left(\mathrm{C}_{s p}{ }^{2}\right.$ will be represented by $\mathrm{C}$ ), $\mathrm{O}-\mathrm{H}$, Lp(lone pair) - $\mathrm{O}$, and $\mathrm{O}-\mathrm{C}_{s p} 3$ bonds. The calculated and experimental bond lengths in the model compounds are compared by type in Table II.

The natural bond length and ihe stretching constant for the $\mathrm{Lp}-\mathrm{O}$ bond are taken to be the same as those of the $\mathrm{Lp}-\mathrm{O}$ (alcohol 
Table I. Force field parameters for furan type oxygen ${ }^{\mathrm{a}}$ and thiophene type sulfur.

\begin{tabular}{crr}
$\pi$ orbital parameters & $\mathrm{O}$ & $\mathrm{S}$ \\
\hline Effective nuclear charge & 4.55 & 5.45 \\
Ionization potential & $17.60 \mathrm{eV}$ & $15.80 \mathrm{eV}$ \\
One center repulsion integral & $19.342 \mathrm{eV}$ & $11.92 \mathrm{eV}$ \\
van der Waals parameters & & \\
Radius: $(r *)$ & $1.740 \AA$ & $2.110 \AA$ \\
Energy: $(\varepsilon)$ & $0.050 \mathrm{kcal}$ & $0.202 \mathrm{kcal}$
\end{tabular}

Stretching parameters

$\begin{array}{lc}\text { Bond type } & l_{0} \\ \mathrm{C}-\mathrm{O} & (\AA) \\ \mathrm{H}-\mathrm{O} & 1.225 \\ \mathrm{LP}-\mathrm{O} & 0.972 \\ \mathrm{C}_{s p}{ }^{3}-\mathrm{O} & 0.600 \\ \mathrm{C}-\mathrm{S} & 1.414 \\ & 1.459\end{array}$

$\begin{array}{cc} & k \\ \text { slope } & \text { (mdyn } / \AA \text { ) } \\ 0.196 & 10.00 \\ & 7.20 \\ & 4.60 \\ 0.397 & 5.36 \\ & 6.471\end{array}$

$\begin{array}{lc}\text { slope } & \begin{array}{c}\text { Bond moment } \\ \text { (debye) }\end{array} \\ 5.44 & 0.95 \\ & 0.70 \\ & -0.75 \\ 4.861 & 0.22 \\ & 1.925\end{array}$

Bending parameters



\section{$\theta_{0}$ (degree) \\ 120.0 (type 1 ) \\ 118.1 (type 2)}

108.0

113.95

122.2

113.6

124.2

106.7

109.0

128.8

107.5

98.5

119.0

120.0 $k\left(\mathrm{mdyn} / \mathrm{rad}^{2}\right)$
0.60
0.60
0.45
0.87
0.35
0.77
0.35
0.54
0.36
0.36
0.70
0.68
0.38
0.40
0.050

$V_{1}(\mathrm{kcal} / \mathrm{mol})$

0.0

0.0

0.0

0.0

$-0.46$

0.0

0.0

$-0.82$

1.00

1.25

0.0

0.0

0.0

$-2.0$

0.0

0.0

0.0

0.0

0.0

0.0

0.0

3.0

$V_{2}(\mathrm{kcal} / \mathrm{mol})$
15.00
15.00
8.30
0.0
2.700
7.50
9.20
9.20
7.00
0.00
0.0
0.0
0.0
15.00
-0.60
0.0
0.0
15.0
15.0
1.7
1.7
15.0

$V_{3}(\mathrm{kcal} / \mathrm{mol})$
0.0
0.0
-0.800
0.25
0.700
0.0
0.0
3.70
0.0
0.50
0.35
0.18
0.40
0.0
0.30
0.0
0.0
2.6
0.0
0.4
0.0
0.5


drogen atom of type 5 if attached to carbon, type 28 if attached to oxygen; $O$, furan type oxygen of type 41 ; Lp is the lone pair, of type 20; and $S$ is the $s p^{2}$ type sulfur atom, of type 42 . 
Table II. Calculated and experimental bond lengths $(\AA)$ and $\mathrm{C}-\mathrm{O} \pi$ bond orders. ${ }^{2}$

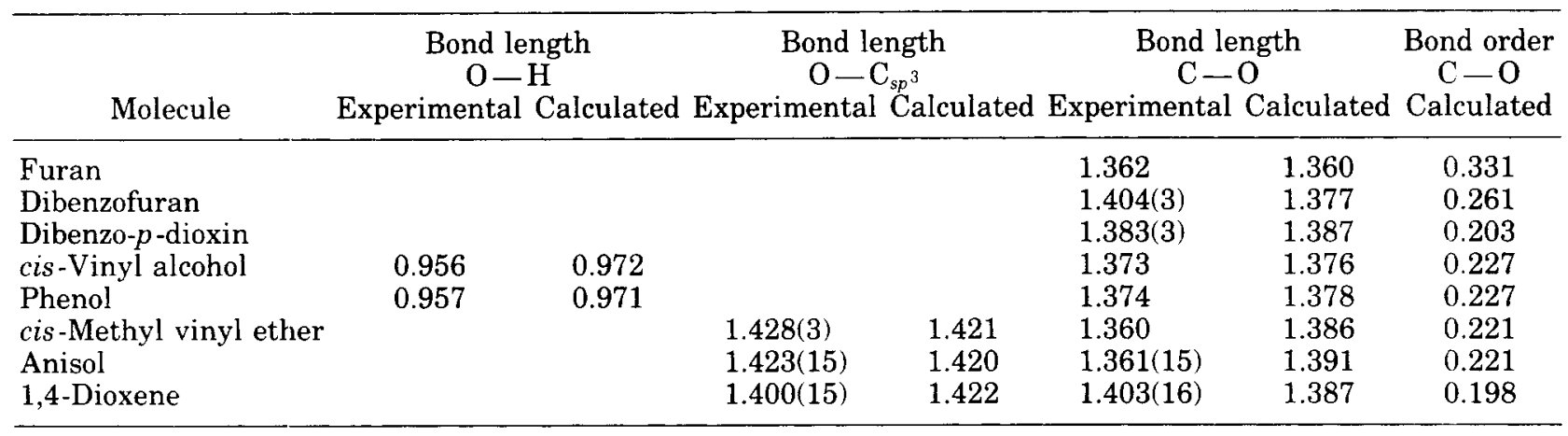

${ }^{a}$ For references to experimental data, see Table VIII.

or ether) bond. The $\mathrm{O}-\mathrm{H}$ and $\mathrm{O}-\mathrm{C}_{s p}{ }^{3}$ are pure sigma bonds, therefore their lengths do not vary much from molecule to molecule. The calculated $\mathrm{O}-\mathrm{H}$ bond lengths are deliberately adjusted to be about $0.020 \AA$ longer than the microwave bond length, which is about the same difference as that between the calculated and the microwave bond length for $\mathrm{C}-\mathrm{H}$ bonds, and is largely due to the fact that an $r_{g}$ value for the bond length is wanted for MM2. The $\mathrm{O}-\mathrm{C}_{s p}{ }^{3}$ bond lengths of the three ether molecules are calculated to be approximately the same, and since their relative lengths do not change with the stretching constant, no further improvement on their agreement with experiment can be made. The $\mathrm{C}-\mathrm{O}$ bond is part of the pi system, and its length and stretching constant vary with the bond order. The open chain alcohols and ethers are calculated to have very similar pi bond orders (ca. 0.22), the calculated bond lengths are therefore very close to each other. Poor agreement is found in dibenzofuran, in which the $\mathrm{C}-\mathrm{O}$ bond is calculated to be too short by at least $0.03 \AA$. Since its bond order is between those of the $\mathrm{C}-\mathrm{O}$ bonds in furan and all of the other molecules, it is obvious there is no way one can fit all of these data at the same time. There seems to be some question about the accuracy of the observed geometry of dibenzofuran as the observed bridge $\mathrm{C}-\mathrm{C}$ length in that molecule is also unusually long. This point will be taken up again later.

Only one bond involving sulfur needs to be considered, namely the $\mathrm{C}-\mathrm{S}$ bond. The parameters arrived at calculate good bond lengths for all sulfur compounds included in this study. The calculated and experimental bond lengths in the model compounds are compared in Table III.

\section{THE BENDING PARAMETERS}

A total of 10 different angle types involving oxygen are represented by the molecules studied. Of these, three are fictious angles involving the lone pair. The bending constants of these are typically assigned a small value (ca. 0.35) and the natural angles are chosen such that the total value of the three angles around the oxygen be as close to $360^{\circ}$ as possible. Bending parameters for corresponding angles in ethers and alcohols are

Table III. Calculated and experimental $\mathrm{C} \longrightarrow \mathrm{S}$ bond lengths (in $\AA$ ) and pi bond order.

\begin{tabular}{lccc}
\hline \multicolumn{1}{c}{ Molecule } & $\begin{array}{c}\text { Bond length } \\
\text { Experimental }\end{array}$ & $\begin{array}{c}\text { Pi bond order } \\
\text { Calculated }\end{array}$ \\
\hline Thiophene & 1.714 & 1.714 & 0.389 \\
1,4-Dithiadiene & 1.78 & 1.781 & 0.194 \\
Thiophthene & 1.73 & 1.723 & 0.374 \\
trans-2,2'-bithiophene & 1.717 & 1.715 & 0.388 \\
Dibenzothiophene & 1.740 & 1.738 & 0.328 \\
Thianthrene & 1.773 & 1.777 & 0.212 \\
trans-1,2-bis(2-thienyl)ethylene & 1.701 & 1.716 & 0.385 \\
\hline
\end{tabular}

${ }^{a}$ For references to experimental data, see Table IX. 
used for $\mathrm{H}-\mathrm{C}_{s p}{ }^{3}-\mathrm{O}$ and $\mathrm{C}_{s p}{ }^{3}-\mathrm{C}_{s p}{ }^{3}-\mathrm{O}$ angles, as these are not known for any of the model compounds. The experimental value of the $\mathrm{H}-\mathrm{C}-\mathrm{O}$ type angle is only known for furan and will be discussed later under the structure of furan. This leaves angles of the types $\mathrm{C}-\mathrm{O}-\mathrm{C}, \mathrm{C}-\mathrm{C}-\mathrm{O}, \mathrm{C}-\mathrm{O}-\mathrm{H}$, and $\mathrm{C}-\mathrm{O}-\mathrm{C}_{s p}{ }^{3}$ that have been measured in more than one molecule. Parameters were chosen to reproduce the experimental data. All of the out-of-plane bending parameters for the furan type oxygen were assigned a value of $0.050 \mathrm{kcal} / \mathrm{mol}$, as were most of those used in the MM2(82) program. The calculated and experimental values for the four types of bond angles just mentioned are presented in Table IV.

The $\mathrm{C}-\mathrm{O}-\mathrm{C}$ angle occurs only in a planar ring structure in the three compounds studied, therefore it is affected by the other bond angles and the bond lengths in the same ring. Since $\mathrm{C}-\mathrm{C}-\mathrm{O}$ angles occur in the same ring, the results represent a comprise between the agreements of $\mathrm{C}-\mathrm{O}-\mathrm{C}$ and $\mathrm{C}-\mathrm{C}-\mathrm{O}$ type angles. Furthermore, in dibenzofuran and dibenzo-p-dioxin, two types of $\mathrm{C}-\mathrm{C}-\mathrm{O}$ angles exist, one with both carbons in the same ring as the oxygen, and the other with one carbon in a benzene ring fused to the one containing the oxygen atom (which will be called the exo $\mathrm{C}-\mathrm{C}$ $\mathrm{O}$ angle). In both dibenzofuran and dibenzo$p$-dioxin, the calculated values are too small for the former and too great for the latter type of angle. In dibenzofuran, the two angles are very different from the natural angle, therefore increasing the bending force constant $k$ would reduce the difference. But increasing $k$ would cause the corresponding angle to increase in furan, and to reduce in ethers and alcohols, thus giving poorer results in those molecules. The $\mathrm{C}-\mathrm{O}-\mathrm{H}$ and $\mathrm{C}-\mathrm{O}-\mathrm{C}_{s p}{ }^{3}$ angles are reproduced in the alcohols and ethers satisfactorily. It should be noted that another molecular mechanics study was simultaneously carried out ${ }^{8}$ for divinyl ether and its derivatives. Care was taken to coordinate it with this study so that identical parameters are used for the same angle type.

Three bond angle types appear for thiophene type compounds. The parameters were derived in a similar way, to find the best fit among all of the compounds considered. The calculated and experimental values for $\mathrm{C}-\mathrm{S}-\mathrm{C}$ and $\mathrm{C}-\mathrm{C}-\mathrm{S}$ types bond angles are listed in Table $\mathrm{V}$. The $\mathrm{C}-\mathrm{S}-\mathrm{C}$ angles are very well fit. The $\mathrm{C}-\mathrm{C}-\mathrm{S}$ angles could be less well but adequately, fit to the experimental data.

\section{THE TORSIONAL PARAMETERS}

Since the furan type molecules studied here except dioxene are planar, and since most molecules exist in only one stable form, it is not possible to uniquely assign the torsional constants in many cases. Experimental studies or $a b$ initio calculations yielded information on the conformational energies and/or rotational barriers of vinyl alcohol, ${ }^{9}$ phenol, ${ }^{10}$ and methyl vinyl ether. ${ }^{11}$ These made possible the determination of the torsional constants of the dihedral angles involved. Table VI contains the experimental

Table IV. Comparison of calculated and experimental bond angles (in degrees). ${ }^{a}$

\begin{tabular}{|c|c|c|c|c|c|c|}
\hline \multirow[b]{2}{*}{ Molecule } & \multicolumn{2}{|c|}{$\mathrm{C}--\mathrm{O}-\mathrm{C}$} & \multicolumn{2}{|c|}{$\mathrm{C}-\mathrm{C}-\mathrm{O}$} & \multicolumn{2}{|c|}{$\mathrm{C}-\mathrm{O}-\mathrm{H}$ or $\mathrm{C}-\mathrm{O}-\mathrm{C}_{s p^{3}}$} \\
\hline & Experimental & Calculated & Experimental & Calculated & Experimental & Calculated \\
\hline Furan & 106.6 & 106.3 & 110.7 & 111.0 & & \\
\hline Dibenzofuran & 104.1 & 106.0 & 112.7 & 111.4 & & \\
\hline & & & exo 124.3 & 127.9 & & \\
\hline Dibenzo-p-dioxin & 116.4 & 117.2 & 121.9 & 121.4 & & \\
\hline cis-Vinyl alcohol & & & exo 117.7 & 119.0 & & \\
\hline 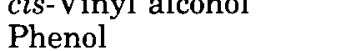 & & & $\begin{array}{l}126.0 \\
121.1\end{array}$ & $\begin{array}{l}121.6 \\
120.4\end{array}$ & $\begin{array}{l}108.9 \\
108.9\end{array}$ & $\begin{array}{l}108.4 \\
108.1\end{array}$ \\
\hline cis-Methyl vinyl ether & & & $127.7(1.4)$ & 126.8 & $118.3(1.1)$ & 119.0 \\
\hline Anisol & & & & & $120.0(2.0)$ & 119.5 \\
\hline 1,4-Dioxene & & & $123.4(.5)$ & 122.1 & & \\
\hline
\end{tabular}

${ }^{a}$ For references to experimental data, see Table VIII. 
Table V. Comparison of Calculated and Experimental Bond Angles (in degrees). ${ }^{a}$

\begin{tabular}{|c|c|c|c|c|c|}
\hline \multirow[b]{2}{*}{ Molecule } & \multicolumn{2}{|c|}{$\mathrm{C}-\mathrm{S}-\mathrm{C}$} & \multicolumn{3}{|c|}{$\mathrm{C}-\mathrm{C}-\mathrm{S}$} \\
\hline & Experimental & Calculated & Exper & rimental & Calculated \\
\hline Thiophene & 92.2 & 92.0 & & 111.5 & 111.6 \\
\hline 1,4-Dithiadiene & 100.2 & 100.8 & & 124.5 & 124.0 \\
\hline \multirow[t]{3}{*}{ Thiophthene } & 91.2 & 91.1 & & 110.2 & 111.4 \\
\hline & & & & 116.5 & 113.1 \\
\hline & & & exo & 135.5 & 135.1 \\
\hline \multirow{2}{*}{ trans-2,2'-bithiophene } & 92.0 & 92.6 & & 111.0 & 111.4 \\
\hline & & & exo & 120.1 & 123.5 \\
\hline \multirow{2}{*}{ Dibenzothiophene } & 91.5 & 91.5 & & 112.3 & 112.4 \\
\hline & & & exo & 126.2 & 126.5 \\
\hline Thianthrene & 100.4 & 101.8 & & & \\
\hline & 93.2 & 92.7 & & 111.3 & 110.3 \\
\hline \multirow[t]{2}{*}{ (2-thienyl) ethylene } & & & & 111.0 & 111.4 \\
\hline & & & exo & 124.4 & 126.1 \\
\hline
\end{tabular}

${ }^{\text {aF }}$ or references to experimental data, see Table IX.

Table VI. Energy differences between different conformations of vinyl alcohol, of phenol, and of methyl vinyl ether.

\begin{tabular}{|c|c|c|c|}
\hline \multirow[b]{2}{*}{ Molecule } & \multirow[b]{2}{*}{ Conformation } & \multicolumn{2}{|c|}{ Relative energy (kcal/mol) } \\
\hline & & Experimental $^{\mathrm{a}}$ & Calculated \\
\hline Vinyl alcohol & $\begin{array}{l}\text { cis, } \omega(\mathrm{C}-\mathrm{C}-\mathrm{O}-\mathrm{H})=0 \\
\text { maximum at } 87^{\circ}\end{array}$ & $\begin{array}{l}0 \\
4.3\left(\omega=87^{\circ}\right)\end{array}$ & $\begin{array}{l}0.0 \\
4.29\left(\omega=87^{\circ}\right)\end{array}$ \\
\hline & trans & 1.8 & 1.81 \\
\hline Phenol & planar, $\omega(\mathrm{C}-\mathrm{C}-\mathrm{O}-\mathrm{H})=0$ & 0 & 0.0 \\
\hline Methyl vinyl ether & $\begin{array}{l}\max 1 \mathrm{mum} \text { at } 90 \\
\text { cis, } \omega\left(\mathrm{C}-\mathrm{C}-\mathrm{O}-\mathrm{C}_{\left.s p^{3}\right)}=0\right. \\
\operatorname{maximum} \text { at } \omega \approx 60^{\circ}\end{array}$ & $\begin{array}{l}3.29-3.47 \\
0 \\
6.33\end{array}$ & $\begin{array}{l}3.37 \\
0.0 \\
6.30\end{array}$ \\
\hline & gauche & $\begin{array}{l}1.15 \pm 0.05 \\
\omega=144^{\circ}\end{array}$ & $\begin{array}{l}1.15 \\
\omega=144^{\circ}\end{array}$ \\
\hline & trans & $1.98 \pm 0.05$ & 1.98 \\
\hline gauche, & $\mathrm{CH}_{3}$ group rotational barrier & 1.47 & 1.70 \\
\hline cis, & $\mathrm{CH}_{3}$ group rotational barrier & $3.83 \pm 0.1$ & 3.49 \\
\hline
\end{tabular}


and 9 for the experimental torsional profiles of phenol and methyl vinyl ether, respectively.

and calculated energies of various conformations of several compounds which were obtained using these constants. What follows will be a presentation of the way the torsional constants were arrived at. To start out, the following assignments were made:

1. The torsional constants for angles $\mathrm{C}-$ $\mathrm{C}-\mathrm{O}-\mathrm{C}, \mathrm{C}-\mathrm{C}-\mathrm{O}-\mathrm{Lp}, \mathrm{H}-\mathrm{C}-$ $\mathrm{O}-\mathrm{C}$, and $\mathrm{H}-\mathrm{C}-\mathrm{O}-\mathrm{Lp}$ were deduced from the study of divinyl ether and its derivatives. ${ }^{8}$

2. Torsional parameters for angles $\mathrm{H}-$ $\mathrm{C}_{s p}{ }^{3}-\mathrm{C}_{s p}{ }^{3}-\mathrm{O}, \mathrm{C}_{s p}{ }^{3}-\mathrm{C}_{s p}{ }^{3}-\mathrm{O}-\mathrm{C}$, $\mathrm{O}-\mathrm{C}-\mathrm{C}-\mathrm{O}$ and $\mathrm{O}-\mathrm{C}_{s p}{ }^{3}-\mathrm{C}_{s p}{ }^{3}-$ $\mathrm{O}$ were available from the MM2 study mentioned earlier. ${ }^{5}$
3. All of the three torsional constants $V_{1}$, $V_{2}$, and $V_{3}$ for angles $\mathrm{H}-\mathrm{C}_{s p} 3-\mathrm{O}-\mathrm{Lp}$ and $\mathrm{C}_{s p^{3}}-\mathrm{C}_{s p}{ }^{3}-\mathrm{O}-\mathrm{Lp}$ were set to equal to zero. (These parameters are redundant.)

4. All angles of the type $\mathrm{X}-\mathrm{C}-\mathrm{C}-\mathrm{Y}$ were assigned $V_{2}$ values of 15.0.

5. The torsional constants of the remaining five types of torsional angles - $\mathrm{C}$ $\mathrm{C}-\mathrm{O}-\mathrm{C}_{s p^{3}}, \mathrm{H}-\mathrm{C}-\mathrm{O}-\mathrm{C}_{s p}{ }^{3}$, $\mathrm{C}-\mathrm{C}-\mathrm{O}-\mathrm{H}, \mathrm{H}-\mathrm{C}-\mathrm{O}-\mathrm{H}$, and $\mathrm{H}-\mathrm{C}_{s p}{ }^{3}-\mathrm{O}-\mathrm{C}-$ were determined to best fit the barrier height of phenol; the barrier height of vinyl alcohol and the angle at which the energy maximum occurs; the energy profile of 
methyl vinyl ether for rotation about the $\mathrm{C}-\mathrm{O}$ bond and for rotation of the methyl group.

The agreement is very good in every case except for the methyl group rotational barriers of the methyl vinyl ethers. The calculated values of the rotational barrier are $0.23 \mathrm{kcal}$ too high for the gauche form and $0.34 \mathrm{kcal}$ too low for the cis form. It is not possible to improve both barriers simultaneously. Because they are both proportional to $V_{3}\left(\mathrm{H}-\mathrm{C}_{s p} 3-\mathrm{O}-\mathrm{C}\right)$, varying $V_{3}$ would not change the difference between the barriers, which in MM2 is due to the differences in van der waal's force between the methyl hydrogens and other atoms in the molecule.

For angles involving the sulfur atom, the $V_{2}$ values for dihedral angles about a $\mathrm{C}-\mathrm{C}$ bond were also set to be 15.0. The other torsional constants were chosen to reproduce dihedral angles observed in the three nonplanar compounds: 1,4-dithiadine, $2,2^{\prime}$-bithiophene, and thianthrene. The calculated and experimental values for the dihedral angles between two planes in these compounds are presented in Table IX.

\section{BOND MOMENTS}

The dipole moments are calculated as the sum of the sigma moments and the pi moments. Pi moments are calculated from the coordinates of the atoms and the pi charges at these sites. Sigma moments are calculated from the molecular geometries and the bond moments. The bond moments studied in this work involving an oxygen atom were chosen to best fit the experimental moment of furan and to minimize the discrepancy between experimental and calculated moments in the other oxygen-containing molecules. Among the sulfur compounds studied, only thiophene and dibenzothiophene have nonzero dipole moments. The bond moment for the $\mathrm{C}-\mathrm{S}$ bond was chosen to reproduce the dipole moment for thiophene. The results are shown in Table VII.

With the SCF scheme used in the current method, the pi electronic charges are considered to be overestimated. ${ }^{3}$ This would lead to overestimated pi dipole moments. The sigma moments are correspondingly underestimated, and hence furan and thiophene have their total moments correctly calcu-
Table VII. Calculated and experimental dipole moments. ${ }^{\mathbf{a}}$

\begin{tabular}{llc}
\hline \multicolumn{1}{c}{ Molecule } & \multicolumn{2}{c}{ Dipole moments (debye) } \\
& Experimental & Calculated \\
\hline Furan & 0.67 & 0.67 \\
Benzofuran & $0.79^{12}$ & 0.96 \\
cis-Vinyl alcohol & $1.016 \pm 0.009$ & 0.96 \\
Phenol & 1.28 & 1.37 \\
cis-Methyl vinyl ether & $0.96 \pm 0.02$ & 0.71 \\
Anisol & $1.30 \pm 0.03^{13}$ & 1.03 \\
1,4-dioxene & $0.939 \pm 0.008$ & 0.75 \\
Thiophene & $0.55^{17 c}$ & 0.55 \\
Dibenzothiophene & $0.83^{18 b}$ & 1.05 \\
\hline
\end{tabular}

${ }^{\text {a }}$ References to experimental data except noted otherwise are the same as those for structures given in Table VIII and Table IX.

lated. The dibenzoderivatives have their dipole moments calculated too high, in part from the effect of the SCF charges in the dibenzo rings, and in part due to the neglect of induced dipoles. ${ }^{36}$

\section{MOLECULAR STRUCTURE}

The calculated and experimental structures of the molecules studied are presented in Table VIII for furan and related compounds, and in Table IX for thiophene and related compounds. Furan is the "proto type" molecule. Its structure was studied and determined with great care and precision. ${ }^{14}$ Efforts were therefore made to best fit its structure. As can be seen from Table VIII, the three moments of inertia were each calculated to within $0.7 \%$ of the measured values. Accuracy in the predicted $\mathrm{C}-\mathrm{O}-\mathrm{C}$ and $\mathrm{C}-\mathrm{C}-\mathrm{O}$ angles was sacrificed somewhat to yield a better geometry for dibenzofuran as was discussed earlier. The angle $\mathrm{H}-\mathrm{C}-\mathrm{O}$ was calculated to be too large by $1.5^{\circ}$ as a result of the small value predicted for the neighboring $\mathrm{C}-\mathrm{C}-\mathrm{H}$ angle. Since the parameters for $\mathrm{C}-\mathrm{C}-\mathrm{H}$ type angle are not adjustable in this work, and since the molecule is planar, further improvement on the value of $\mathrm{O}-\mathrm{C}-\mathrm{H}$ would have to be made at the expense of the $\mathrm{C}-\mathrm{C}-\mathrm{O}$ angle. It is interesting to note that the same was found to be true in the other five-member heterocycles studied. In pyrrole, the $\mathrm{N}-$ $\mathrm{C}-\mathrm{H}$ angle; in thiophene, the $\mathrm{S}-\mathrm{C}-\mathrm{H}$ angle are calculated to be too large while the neighboring $\mathrm{C}-\mathrm{C}-\mathrm{H}$ angles are too 
small. The X-ray structure of dibenzofuran ${ }^{15}$ is given in Table VIII. The only other study found in the literature ${ }^{16}$ gives a virtually identical structure. Although these X-ray structures are not of very high quality $(R=$ 0.073 and $R=0.10$ ), the discrepancies between the calculated and experimental lengths for the $\mathrm{C}-\mathrm{O}$ and for the bridged $\mathrm{C}-\mathrm{C}$ bonds are still astounding. The calcu- lated bond lengths are $1.377 \AA$ and $1.448 \AA$ vs. $1.404 \AA$ and $1.481 \AA$ experimentally. Since the corresponding $\mathrm{C}-\mathrm{C}$ lengths in thiophene $e^{17}$ and dibenzothiophene ${ }^{18}$ are $1.423 \AA$ and $1.441 \AA$ and those in pyrrole and carbazole (and its derivatives) are $1.417 \AA$ and $1.438 \AA$ respectively, it does seem strange that the said bonds in dibenzofuran should be $0.050 \AA$ longer than in

Table VIII. Experimental and calculated structure ${ }^{a}$ for Furan and related molecules.

\begin{tabular}{|c|c|c|c|c|}
\hline & \multicolumn{2}{|c|}{ Experimental } & \multicolumn{2}{|c|}{ Calculated } \\
\hline Furan $^{14}$ & $\begin{array}{c}1-2 \\
2-3 \\
3-4 \\
2-6 \\
3-7 \\
2-1-5 \\
1-2-3 \\
2-3-4 \\
1-2-6 \\
3-2-6 \\
2-3-7 \\
I_{a} \\
I_{b} \\
I_{c}\end{array}$ & $\begin{array}{c}1.362 \\
1.361 \\
1.430 \\
1.075 \\
1.077 \\
106.6 \\
110.6 \\
106.1 \\
116.0 \\
133.4 \\
126.1 \\
8.885 \\
9.079 \\
17.970\end{array}$ & & $\begin{array}{c}1.360 \\
1.364 \\
1.428 \\
1.102 \\
1.102 \\
106.3 \\
111.0 \\
105.9 \\
117.5 \\
131.6 \\
127.1 \\
8.837 \\
9.141 \\
17.978\end{array}$ \\
\hline Dibenzofuran ${ }^{b}$ & $\begin{array}{c}1-2 \\
1-13 \\
2-3 \\
3-4 \\
4-5 \\
5-6 \\
5-13 \\
12-13 \\
2-1-13 \\
1-2-3 \\
2-3-4 \\
3-4-5 \\
4-5-6 \\
4-5-14\end{array}$ & $\begin{array}{c}1.389 \\
1.384 \\
1.385 \\
1.388 \\
1.385 \\
1.404 \\
1.393 \\
1.481 \\
117.9 \\
121.9 \\
120.9 \\
116.7 \\
124.3 \\
123.0\end{array}$ & & $\begin{array}{c}1.391 \\
1.402 \\
1.410 \\
1.392 \\
1.403 \\
1.377 \\
1.399 \\
1.448 \\
117.3 \\
121.2 \\
121.3 \\
117.7 \\
127.9 \\
120.7\end{array}$ \\
\hline & $\begin{array}{c}6-5-13 \\
5-6-7 \\
5-13-12 \\
13-1-15 \\
1-2-16 \\
2-3-17 \\
3-4-18\end{array}$ & $\begin{array}{l}112.7 \\
104.1 \\
105.3 \\
122.5 \\
119.5 \\
117.9 \\
123.4\end{array}$ & & $\begin{array}{l}111.4 \\
106.0 \\
105.6 \\
121.1 \\
119.4 \\
119.4 \\
121.5\end{array}$ \\
\hline Dibenzo-p-dioxin ${ }^{c, d}$ & $\begin{array}{c}1-2 \\
1-14 \\
2-3 \\
5-14 \\
5-6 \\
2-1-14 \\
1-2-3 \\
1-14-5 \\
14-5-6 \\
5-6-7 \\
4-5-6\end{array}$ & $\begin{array}{c}1.400(4) \\
1.387(3) \\
1.374(4) \\
1.387(4) \\
1.382(3) \\
119.1(3) \\
120.5(3) \\
120.5(2) \\
121.9(2) \\
116.3(2) \\
117.7(5)\end{array}$ & $\begin{array}{r}1.383(8) \\
\\
121.8(6) \\
116.4(5)\end{array}$ & $\begin{array}{c}1.398 \\
1.398 \\
1.394 \\
1.406 \\
1.387 \\
120.6 \\
119.9 \\
119.6 \\
121.4 \\
117.2 \\
119.0\end{array}$ \\
\hline cis-Vinyl Alcohol ${ }^{22}$ & $\begin{array}{l}1-2 \\
1-3 \\
1-4 \\
2-5\end{array}$ & $\begin{array}{l}1.373 \\
1.332 \text { (assigned) } \\
0.956 \text { (assigned) }\end{array}$ & & $\begin{array}{l}1.376 \\
1.341 \\
1.103 \\
0.972\end{array}$ \\
\hline
\end{tabular}


Table VIII. (continued)

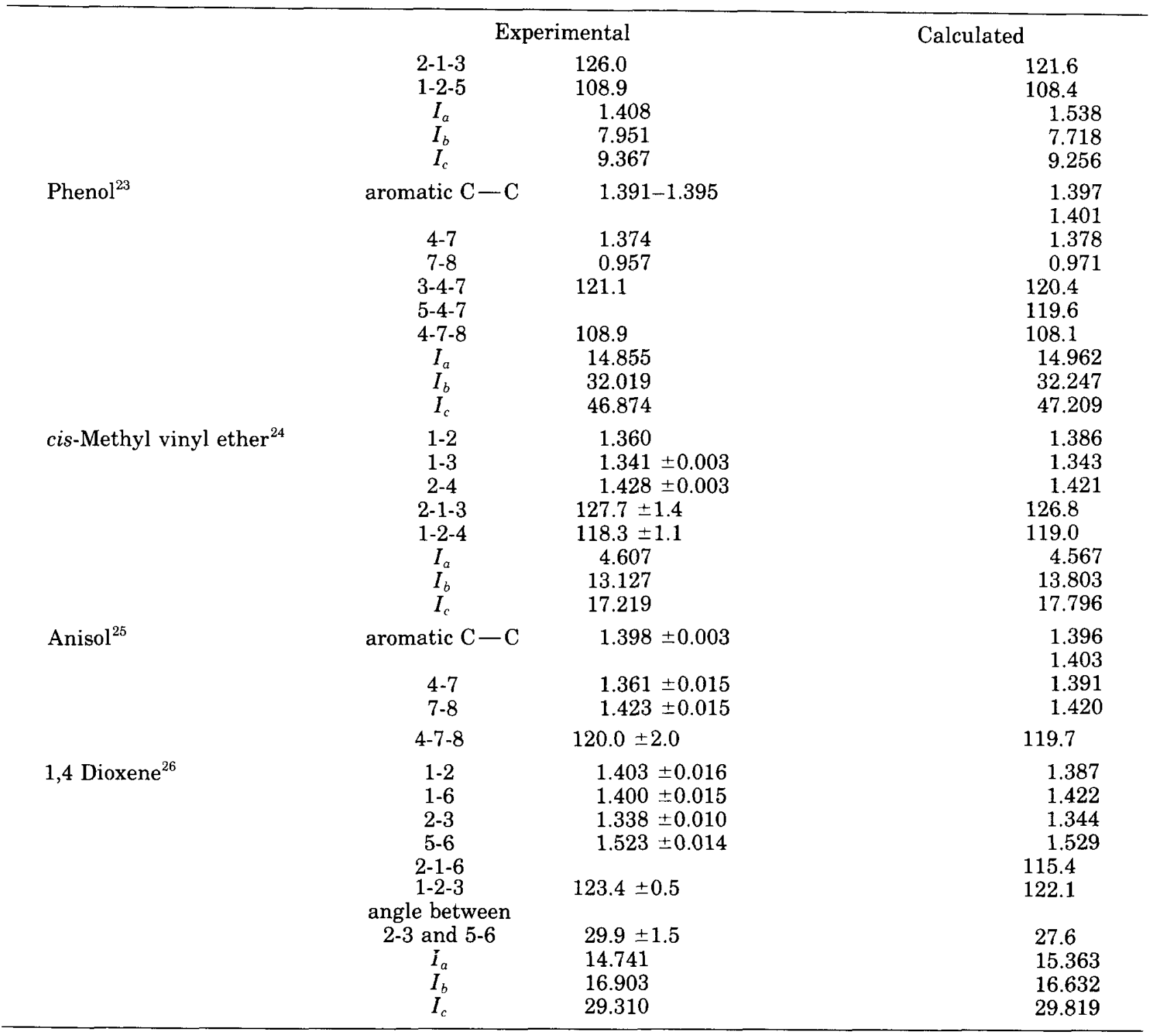

${ }^{a}$ Bond lengths in $\AA$, bond angles in degrees, and moments of inertia in $\mathrm{g} \mathrm{cm}^{2} \times 10{ }^{39}$

${ }^{b}$ Reference $15, \mathrm{X}$-ray, $R=0.073$, deviations are $0.003 \AA$ and $0.13^{\circ}$ for bond length and bond angle not involving $\mathrm{H}$. Values corrected for thermal motion except those involving $\mathrm{H}$ atoms.

'Reference 21a, X-ray, $R=0.103$.

${ }^{\mathrm{d}}$ Reference $21 \mathrm{~b}, \mathrm{X}$-ray, $R_{l}=0.057, R_{2}=0.062$.

Table IX. Experimental and calculated structure ${ }^{\text {a }}$ for Thiophene and related molecules.

\begin{tabular}{|c|c|c|c|}
\hline & & Experimental & Calculated \\
\hline \multirow[t]{13}{*}{ Thiophene ${ }^{17}$} & $1-2$ & 1.714 & 1.714 \\
\hline & $2-3$ & 1.370 & 1.369 \\
\hline & $3-4$ & 1.424 & 1.420 \\
\hline & $2-6$ & 1.078 & 1.102 \\
\hline & $3-7$ & 1.081 & 1.102 \\
\hline & $2-1-5$ & 92.2 & 92.0 \\
\hline & $1-2-3$ & 111.5 & 111.6 \\
\hline & $2-3-4$ & 112.5 & 112.4 \\
\hline & $1-2-6$ & 119.8 & 123.5 \\
\hline & $4-3-7$ & 124.3 & 123.7 \\
\hline & $I_{a}$ & 10.44 & 10.43 \\
\hline & $I_{b}^{a}$ & 15.50 & 15.49 \\
\hline & $I_{\mathrm{c}}^{0}$ & 25.95 & 25.92 \\
\hline
\end{tabular}


Table IX. (continued)

\begin{tabular}{|c|c|c|c|}
\hline & & Experimental & Calculated \\
\hline 1,4-Dithiadiene $e^{30}$ & $\begin{array}{c}1-2 \\
2-3 \\
2-1-6 \\
1-2-3 \\
\omega\end{array}$ & $\begin{array}{l}1.78 \text { (av.) } \\
1.29 \text { (av.) } \\
100.2 \\
124.5 \\
137.1\end{array}$ & $\begin{array}{l}1.781 \text { (av.) } \\
1.348 \text { (av.) } \\
100.8 \\
124.0 \\
136.6\end{array}$ \\
\hline Thiophthene ${ }^{32}$ & $\begin{array}{c}1-2 \\
1-5 \\
2-3 \\
3-4 \\
4-5 \\
2-1-5 \\
1-2-3 \\
1-5-4 \\
1-5-6 \\
2-3-4 \\
3-4-5\end{array}$ & $\begin{array}{c}1.72 \\
1.74 \\
1.36 \\
1.41 \\
1.36 \\
91.2 \\
116.5 \\
110.2 \\
135.5 \\
111.7 \\
114.3\end{array}$ & $\begin{array}{c}1.733 \\
1.722 \\
1.370 \\
1.425 \\
1.382 \\
91.1 \\
113.1 \\
111.4 \\
135.1 \\
110.9 \\
113.5\end{array}$ \\
\hline trans $-2,2^{\prime}$-Bithiophene $\mathrm{e}^{31}$ & $\begin{array}{c}1-2 \\
1-5 \\
2-3 \\
3-4 \\
5-6 \\
2-1-5 \\
1-2-3 \\
1-5-6 \\
2-3-4 \\
1-5-6-10\end{array}$ & $\begin{array}{c}1.717 \\
1.717 \\
1.357 \\
1.433 \\
1.480 \\
92.0 \\
111.0 \\
120.1 \\
116.0 \\
33.8\end{array}$ & $\begin{array}{c}1.711 \\
1.718 \\
1.369 \\
1.420 \\
1.469 \\
92.5 \\
111.4 \\
123.5 \\
112.5 \\
27.0\end{array}$ \\
\hline Dibenzothiophene $^{18}$ & $\begin{array}{c}1-2 \\
2-3 \\
3-4 \\
4-5 \\
5-6 \\
6-7 \\
2-7 \\
7-8 \\
2-1-13 \\
1-2-7 \\
1-2-3 \\
2-7-8 \\
6-7-8\end{array}$ & $\begin{array}{r}1.740 \\
1.386 \\
1.384 \\
1.385 \\
1.370 \\
1.392 \\
1.409 \\
1.441 \\
91.5 \\
112.3 \\
126.2 \\
111.9 \\
129.3\end{array}$ & $\begin{array}{c}1.738 \\
1.409 \\
1.387 \\
1.411 \\
1.387 \\
1.410 \\
1.401 \\
1.447 \\
91.5 \\
112.4 \\
126.5 \\
111.9 \\
128.2\end{array}$ \\
\hline Thianthrene $^{33}$ & $\begin{array}{c}1-2 \\
2-3 \\
3-4 \\
4-5 \\
2-7 \\
2-1-14 \\
\omega\end{array}$ & $\begin{array}{c}1.773 \\
1.385 \\
1.374 \\
1.376 \\
1.379 \\
100.4 \\
128.1\end{array}$ & $\begin{array}{c}1.777 \\
1.399 \\
1.398 \\
1.394 \\
1.408 \\
101.8 \\
135.3\end{array}$ \\
\hline $\begin{array}{l}\text { trans-1,2-bis(2-thienyl) } \\
\text { ethylene }^{34}\end{array}$ & $\begin{array}{c}1-2 \\
1-5 \\
2-3 \\
3-4 \\
4-5 \\
5-6 \\
6-7 \\
2-1-5 \\
1-2-3 \\
1-5-4 \\
1-5-6 \\
5-6-7 \\
2-3-4\end{array}$ & $\begin{array}{c}1.701 \\
1.701 \\
1.351 \\
1.44 \\
1.40 \\
1.457 \\
1.309 \\
93.2 \\
111.0 \\
111.3 \\
124.4 \\
125.8 \\
114.4\end{array}$ & $\begin{array}{c}1.711 \\
1.721 \\
1.369 \\
1.420 \\
1.375 \\
1.463 \\
1.355 \\
92.7 \\
111.4 \\
110.3 \\
126.1 \\
124.2 \\
112.4\end{array}$ \\
\hline
\end{tabular}

${ }^{a}$ Bond lengths in $\AA$, bond angles in degree, and moments of inertia in $\mathrm{g} \mathrm{cm}^{2} \times 10^{39}$ 
Table $\mathrm{X}$. The $\mathrm{C}-\mathrm{O}$ and bridged $\mathrm{C}-\mathrm{C}$ bond lengths in dibenzofuran and its derivatives.

\begin{tabular}{llll}
\hline \multicolumn{1}{c}{ Molecule } & \multicolumn{2}{c}{ Bond length, $\AA$} & \\
& $\mathrm{C}-\mathrm{O}$ & $\mathrm{C}-\mathrm{C}$ & \\
\hline Dibenzofuran & 1.404 & 1.481 & (exptl) $^{\mathrm{a}}$ \\
2,3,7,8-tetrachlorodibenzofuran & 1.385 & 1.448 & (exptl) $^{\mathrm{b}}$ \\
1,4-dimethyl-5-hydroxy-7-acetyldibenzofuran & 1.400 & 1.455 & (exptl) $^{\mathrm{c}}$ \\
2,8-dimethoxydibenzofuran & $1.386,1.375$ & 1.457 & (exptl) $^{\mathrm{d}}$ \\
Dibenzofuran & 1.378 & 1.447 & (calcd) $^{2}$ \\
\hline
\end{tabular}

${ }^{\mathrm{a}}$ Reference $15, \mathrm{X}$-ray, $R=0.073$.

${ }^{\text {b}}$ Reference 27, X-ray, $R=0.042$.

'Reference 28, X-ray, $R=0.056$.

${ }^{\mathrm{d}}$ Reference 29, X-ray, $R=0.04$.

furan. In addition, the furan moities in several dibenzofuran derivatives do not differ very much from furan itself. The $\mathrm{C}-\mathrm{O}$ and the bridged $\mathrm{C}-\mathrm{C}$ bond lengths of a collection of these derivatives are shown in Table $\mathrm{X}$ for comparison with the calculated and experimental bond lengths of dibenzofuran. The 1.481 value seems inconsistent with the rest of the data, and appears to be an artifact. $^{37}$

\section{CONCLUSIONS}

The structures of heterocycles, and other conjugated systems containing furan-type oxygen or thiophene-type sulfur may now be studied with the molecular mechanics (MM2) method, and the calculations generally yield reliable results.

\section{References}

1. U. Burkert and N.L. Allinger, Molecular Mechanics, American Chemical Society, Washington, D. C., 1982. Also see the MM2 manual (supplied with the program, see ref. 4) for a more detailed explanation of the material.

2. J.T. Sprague, J. C. Tai, Y. Yuh, and N. L. Allinger, J. Comput. Chem., 8, 581 (1987).

3. J. C. Tai and N. L. Allinger, J. Am. Chem. Soc., 110,2050 (1988).

4. The 1982 version of the program will treat conjugated hydrocarbons. Conjugated nitrogen was added to the 1985 version, and the $\mathrm{O}$ and $\mathrm{S}$ compounds to this 1987 version. All of these programs are available to academic users from the Quantum Chemistry Program Exchange, (University of Indiana, Bloomington, IN 47405) and to commercial users from Molecular Design Limited (2132 Farallon Drive, San Francisco, CA 94577).

5. H. Dodziuk, H. von Voithenberg, and N. L. Allinger, Tetrahedron, 38, 2811 (1982).

6. J. Hinze and H. H. Jaffé, J. Am. Chem. Soc., 84, 540 (1962).
7. J.C. Tai and N.L. Allinger, Theoret. Chim. Acta (Berl.), 15, 133 (1969).

8. J. P. Bowen, V. V. Reddy, D. Patterson, Jr., and N. L. Allinger, J. Org. Chem ., 53, 5471 (1988).

9. R. H. Nobes, L. Radom, and N. L. Allinger, J. Mol. Struct., 85, 185 (1981).

10. a. T. Pedersen, N.W. Larsen, and L. Nygaard, J. Mol. Struct., 4, 59 (1969). b. H. Forest and B.P. Dailey, J. Chem. Phys., 45, 1736 (1966). c. H. D. Bist and D. R. Williams, Bull. Am. Phys. Soc., 11, 826 (1966).

11. J. R. Durig and D. A.C. Compton, J. Chem. Phys., 69, 2028 (1978).

12. Values quoted by J. Koller, A. Azman, and N. Trinajstic, Z. Naturforsch Teil A., 29, 624(Eng.) (1974), from J. Phys. Chem. USSR, 12, 479 (1938).

13. N. L. Allinger, J. J. Maul, and M. J. Hickey, J. Org. Chem., 36, 2747 (1971).

14. a. B. Bak, D. Christensen, W. B. Dixon, L. HansenNygaard, J. Rastrup-Andersen, and M. Schottländer, J. Molecular Spectroscopy, 9, 124 (1962). b. F. Mata, M. Martin, and G. O. Soerensen, $J$. Mol. Struct., 48, 157 (1978).

15. O. Dideberg, L. DuPont, and J.M. André, Acta Cryst., B28, 1002 (1972).

16. A. Banerjee, Acta Cryst., B29, 2070 (1973).

17. a. R. D. Brown, F. R. Burden, and P.D. Godfrey, J. Mol. Spect., 25, 415 (1968). b. B. Bak, D. Christensen, L. Hansen-Nygaard, and J. RastrupAndersen, J. Mol. Spect., 7, 58 (1961). c. B. Harris, R.J.W. Le Fevre, and E.P. A. Sullivan, J. Chem. Soc., 1622 (1953).

18. a. R.M. Schaffrin and J. Trotter, J. Chem. Soc. (A), 1561 (1970). b. R.G. Charles and H. Freiser, J. Amer. Chem. Soc., 72, 2233 (1950).

19. L. Nygaard, J. T. Nielsen, J. Kirchheiner, G. Maltesen, J. Rastrup-Andersen, and G. O. Sørensen, J. Mol. Struc., 3, 491 (1969).

20. J. J. Stezowski, W. Binder and N. Karl, Acta Cryst., B38, 2912 (1982).

21. a. M. Senma, Z. Taira, T. Taga, and K. Osaki, Cryst. Struc. Comm., 2, 311 (1973). b. P. Singh and J.D. McKinney, Acta Cryst., 34B, 2956 (1978).

22. S. Saito, Chem. Phys. Lett., 42, 399 (1976).

23. N. W. Larsen, J. Mol. Struct., 51, 175 (1979).

24. P. Cahill, L. P. Gold, and N. L. Owen, J. Chem. Phys., 48, 1620 (1968).

25. H.M. Seip and R. Seip, Acta Chem. Scand., 27, 4024 (1973).

26. J.A. Wells and T. B. Malloy, Jr., J. Chem. Phys., 60, 2132 (1974).

27. C. R. Hubbard, A. D. Mighell, and I. H. Pomerantz, 
Acta Cryst., B34, 2381 (1978).

28. M. A. ElSohly, D. J. Slatkin, J.E. Knapp, N.J. Doorenbos, M. W. Quimby, P.L. Schiff, Jr., E. M. Gopalakrishna and W. H. Watson, Tetrahedron, 33, 1711 (1977).

29. J.-E. Berg, B. Karlsson, A.-M. Pilotti, and A.-C. Söderholm, Acta Cryst., B34, 2041 (1978).

30. P. A. Howell, R. M. Curtis, and W. N. Lipscomb, Acta Cryst., 7, 498 (1954).

31. a. G. J. Visser, G. J. Heeres, J. Wolters, and A. Vos, Acta. Cryst., B24, 467 (1968). b. A. Almenningen, O. Bastiansen, and P. Svendsas, Acta. Chem. Scand., 12, 1671 (1958).

32. E. G. Cox, R.J.J.H. Gillot, and G. A. Jeffrey, Acta Cryst., 2, 356 (1949).

33. I. Rowe and B. Post, Acta Cryst., 11, 372 (1958).

34. V.G. Ruban and D. Zobel, Acta Cryst., B31, 2632 (1975).

35. R.D. Brown and M. L. Heffernan, Australian J. Chem., 12, 319 (1959).

36. L. Dosen-Micovic, D. Jeremic, and N. L. Allinger, J. Am. Chem. Soc., 105, 1716 (1983); ibid., 105, 1723 (1983)

37. A reviewer has asked us to comment on the agreement between the present work and the theoretical calculations by K.K. Baldridge and M.S.
Gordon, J. Am. Chem. Soc., 110, 4204 (1988), and to also discuss heat of formation calculations with heterocycles. The article cited appeared after this work had been completed, and was therefore not considered earlier. Since the calculations are approximately at the Hartree-Fock level, there is no allowance for electron correlation. The bond lengths obtained for multiple bonds at the Hartree-Fock level are extremely inaccurate, and in addition, one obtains $r_{e}$ rather than $r_{g}$ bond lengths, which cannot be directly compared. Accordingly, it does not seem that any very useful comparison can be made. The geometries calculated at the Hartree-Fock level are very roughly the same as those found experimentally, or in this work. As far as heat of formation calculations, we were informed about two years ago by W. Steele that his group had remeasured the heats of combustion of many heterocyclic compounds, and found that there are serious discrepancies between their current values and those reported in the earlier literature. We did not feel that it was worthwhile to try to fit to the literature data under those circumstances, and have decided to wait until Dr. Steele's data are published, and can be critically examined. 